OPEN ACCESS

Edited by:

Jiapeng Huang,

University of Louisville, United States

Reviewed by:

Massimiliano Sorbello,

Gaspare Rodolico Hospital, Italy

Andre M. Japiassu,

Oswaldo Cruz Institute, Oswaldo Cruz

Foundation (Fiocruz), Brazil

*Correspondence:

Lina Zhang

zln7095@163.com

Zhaoxin Qian

xyqzx@csu.edu.cn

†These authors have contributed equally to this work

Specialty section

This article was submitted to Intensive Care Medicine and

Anesthesiology,

a section of the journal

Frontiers in Medicine

Received: 02 May 2020

Accepted: 27 July 2020

Published: 11 August 2020

Citation:

Peng M, Qian Z and Zhang L (2020)

Care for Critical III Patients With

COVID-19: Establishment of a

Temporary Intensive Care Unit in an Isolated Hospital. Front. Med. 7:519.

doi: 10.3389/fmed.2020.00519

\section{Care for Critical III Patients With COVID-19: Establishment of a Temporary Intensive Care Unit in an Isolated Hospital}

\author{
Milin Peng 1,2, Zhaoxin Qian ${ }^{2,3 * t}$ and Lina Zhang ${ }^{1,2 * t}$ \\ ${ }^{1}$ Department of Critical Care Medicine, Xiangya Hospital, Central South University, Changsha, China, ${ }^{2}$ National Clinical \\ Research Center for Geriatric Disorders, Xiangya Hospital, Central South University, Changsha, China, ${ }^{3}$ Department of \\ Cardiovascular, Xiangya Hospital, Central South University, Changsha, China
}

The current global spread of COVID-19, a highly contagious disease, has challenged healthcare systems, and placed immense burdens on medical staff globally. With a sharp increase in the number of newly confirmed cases and the rapid progression of the disease into a critically ill state, overstretched critical care units have had to contend with a shortage of beds, specialist personnel, and medical resources. Temporary intensive care units (ICUs) were therefore set up in isolated hospitals to provide the required standardized care for all severe cases. The current paper describes the authors' experience of setting up and managing such an ICU in Wuhan, Hubei Province, China, from the identification of critically ill COVID-19 patients through to the arranging and equipping of the unit, providing training and protection for staff, and standardizing all aspects of care.

Keywords: COVID-19, management, severe, temporary, intensive care unit

\section{INTRODUCTION}

Coronavirus Disease 2019 (COVID-19), caused by severe acute respiratory syndrome coronavirus 2 (SARS-CoV-2), is highly contagious. In recognition of the global threat it poses, on March 11, 2020, the World Health Organization (WHO) declared COVID-19 to be a pandemic. By July 22, 2020, the total officially confirmed cases in China reached 86,152 with 4,653(5.4\%) having died since the outbreak began in December 2019 (https://covid19.who.int/). COVID-19 has high mortality throughout the world, being especially high in Italy $(n=236,076$, mortality with $32,867 / 236,076)$, Spain $(n=264,836$, mortality with $28,422 / 264,836)$, Russia $(n=783,328$, mortality with $12,580 / 783,328)$, Brazil $(n=2,098,389$, mortality with $79,488 / 2,098,389)$, the United States $(n$ $=3,748,248$, mortality with $139,964 / 3,748,248)$, and South Africa $(n=373,628$, mortality with 5,173/373,628) (https://covid19.who.int/, https://www.epicentro.iss.it/en/coronavirus/bollettino/ Infografica_10giugno\%20ENG.pdf). The high incidence and mortality of COVID-19 puts pressure on the need for urgent and special requirements for global medical resources and infrastructures.

\section{PURPOSE AND SIGNIFICANCE OF A TEMPORARY COVID-19 ICU}

Data provided by the Chinese Center for Disease Control and Prevention revealed a total of 44,672 confirmed COVID-19 cases in China by February 11, 2020. Of these, the majority (87\%) were aged 
between 30 and 79, while 3\% were aged 80 or more. A total of $14 \%$ of these patients were, or had been, severely ill, and $5 \%$ required critical care (1). Data from a single-center, retrospective study of 52 critically ill COVID-19 patients showed that $61.5 \%$ died at 28 days, $71 \%$ required mechanical ventilation, and $67 \%$ had acute respiratory distress syndrome (ARDS). Patients who died from the disease were recorded longer lingering time from onset of symptoms to ICU admission than those who survived (2).

As the number of newly-confirmed and critical COVID-19 cases rose sharply from December 2019 onwards in Wuhan, isolated hospitals charged with caring for such patients had to solve immense challenges in terms of finding sufficient bed space, personnel, and resources, particularly in relation to the provision of care for the critically ill patients (3). As COVID-19 is characterized by a high rate of contagion and rapid progression coupled with a high mortality rate, especially in the case of critical patients, it was essential to identify potentially critical cases at the earliest possible stage so they could be transferred to ICU timely to achieve necessary respiratory or circulation support in order to reduce mortality rates (4).

Given the shortage of critical care facilities and resources in isolated hospitals (5), the establishment of temporary ICUs in such hospitals was an essential part of the infrastructure for providing care to critically ill COVID-19 patients. The government thus made the decision to allocate an estimated 2,500 beds in three general hospitals in the city of Wuhan as temporary isolated wards for the treatment of severely infected patients. Over 3,000 medical personnel, including up to 1,000 ICU doctors and nurses, were called together from elsewhere in China to form centralized, specialist rescue teams in each isolated hospital. Each member of the teams represented a different department; thus, uniform and normative team management and patient care were challenging. Existing medical resources were leveraged to meet the needs of these ICUs, and the training of non-ICU staff was also critically important.

Over the course of a month in Wuhan, after the temporary ICU was established, a total of 157 critically ill patients were admitted into our temporary ward; they had characteristics of a mean age at 62 years old, a mean hospital stay at 16.01 days, $14.0 \%$ requiring invasive or non-invasive mechanical ventilation, and $3.82 \%$ died at discharge. Hence, the current paper shares best practices gleaned from the establishment and management of temporary ICUs in isolated hospitals during the epidemic in Wuhan; the centralization of severe confirmed cases enabled reintegration and maximum use of existing medical resources, thus facilitating effective professional treatments for COVID19 patients.

\section{ESTABLISHMENT OF A TEMPORARY COVID-19 ICU}

On February 7, 2020, a national medical team from Xiangya Hospital, Hunan, took over the 51-bed ophthalmic ward in the Union Hospital Tongji Medical College Huazhong University of Science and Technology, Wuhan, in response to the insufficient number of ICU beds in isolated hospitals to cope with the rapidly increasing numbers of cases presenting with COVID19. Combining the characteristics of the ward and taking into consideration severe cases, we planned to establish a temporary ICU in the Ophthalmic Ward; however, given its previous use, not all beds were supplied with sufficient oxygen pressure to run the necessary ventilators.

\section{Early Identification and Sorting of Critical Cases}

The first stage in the care of COVID-19 patients is to identify those who are critically ill. For this purpose, we modified the National Early Warning Score (News) (6) and SOFA score and added two further predicted risk factors for severe COVID19 infection: age $\geq 66$ years old $(2,7,8)$ and persistent lymphocytopenia $(2,8,9)$ (Figure 1). Post-admission, critically ill patients were sorted into one of four risk categories on the basis of their scores on the severity grading scales: mild, moderate, critical, and severe critical. It was important to recognize that critically ill patients who presented with silent hypoxemia (severe hypoxemia without signs of respiratory distress), particularly older ones, required vigilant monitoring. Initially, due to the lack of severe respiratory distress symptoms at the early stage of COVID-19 in some severe confirmed patients, clinicians might delay tracheal intubation, and invasive ventilation. This postponing would bring disastrous consequences for these patients. Hence, early identification of severe critical patients was crucial in enabling personnel to offer optimized treatment within the temporary ICU in the shortest time.

\section{Dividing the Ward Into Sectors}

The ward was divided into three sectors according to the results of the severity grading scales to facilitate clinical management (Figures 2, 3).

The first sector, containing 12 beds supplied with sufficient oxygen pressure to run ventilators, was designated for the management of severe critically ill patients, including those requiring invasive ventilator support or prone ventilation, exhibiting hemodynamic instability. This sector was located close to the nurses' and doctors' workstations, enabling staff to monitor patients closely and provide immediate attention. The beds were placed at least two meters apart to prevent cross-infection. Figure 4 displays the special medical equipment required in the temporary ICU, including non-invasive and invasive ventilators, high-flow nasal cannula (HFNC), renal replacement machines, extracorporeal membrane oxygenation machines, videobronchoscopes (with external monitor), equipment to monitor central venous pressure (CVP) or invasive arterial blood pressure, ultrasound machines, videolaryngoscopes, infusion or syringe pumps, vibrating expectoration machines, and closed tracheal suction catheters.

The second sector of the temporary ICU consisted of a ring of 25 beds outside the critical care sector and was designated for the care of moderate to critical patients, typically requiring lowparameter high flow oxygen therapy with a maximum flow rate of $40 \mathrm{~L} / \mathrm{min}$ and inspired oxygen $(\mathrm{FiO} 2)$ of $50 \%$, or mask oxygen support with a maximum flow of $5 \mathrm{~L} / \mathrm{min}$. The third part, which consisted of 14 beds around the perimeter of the ward, was for 


\begin{tabular}{|c|c|c|c|c|c|c|c|}
\hline \multicolumn{8}{|c|}{ Modified National Early Warning Score (News) in COVID-19 infection } \\
\hline Parameters & 3 & 2 & 1 & $\mathbf{0}$ & 1 & 2 & 3 \\
\hline $\begin{array}{l}\text { Respiration rate } \\
\text { (breaths/min) }\end{array}$ & $\leq 8$ & & $9-11$ & $12-20$ & & $21-24$ & $\geq 25$ \\
\hline Oxygen saturation, $\%$ & $\leq 91$ & $92-93$ & $94-95$ & $\geq 96$ & & & \\
\hline Any supplemental O2? & & Yes & & No & & & \\
\hline Temperature $\left({ }^{\circ} \mathrm{C}\right)$ & $\leq 35.0$ & & $35.1-36.0$ & $36.1-38.0$ & $38.1-39.0$ & $\geq 39.1$ & \\
\hline Systolic BP (mmHg) & $\leq 90$ & $91-100$ & $101-110$ & $111-219$ & & & $\geq 220$ \\
\hline Heart/pulse rate (beats/min) & $\leq 40$ & & $41-50$ & $51-90$ & $91-110$ & $111-130$ & $\geq 131$ \\
\hline $\begin{array}{l}\text { Level of consciousness } \\
\text { (AVPU) }\end{array}$ & & & & A & & & V,P,or U \\
\hline Age & & & & $<66$ & & $66-79$ & $\geq 80$ \\
\hline Lymphocytopenia, $\times 10^{9} / \mathrm{L}$ & $\leq 0.62$ & & & $>0.74$ & & & \\
\hline
\end{tabular}

FIGURE 1 | Early classification of critically COVID-19 patients. BP, blood pressure, level of consciousness; A, Alert; V, Responds to voice; P, Responds to pain; U, Unresponsive.

the use of patients identified as moderate, or who were in the recovery stage or requiring nasal catheter oxygen.

\section{COVID-19 Infection Special Intensive Care Teams Establish}

With insufficient trained ICU personnel to meet demand, we set up a multidisciplinary intensive care team led by senior intensive care specialists, and an intensive nurse team led by experienced intensive care nurses. Our first task was to evaluate isolation conditions, after which we divided the ward into inner and outer zones to give workers a space in which they could rest safely. Since every patient under our care was suffering from the same disease, we then took steps to standardize treatments by establishing protection strategy for each healthcare operation, for example routine medical care, tracheal intubation, and percutaneous tracheotomy.

\section{Protecting Patients and Health Workers}

Preventing a nosocomial outbreak of COVID-19 through transmission from patients to healthcare workers was of vital importance. To this end, every health worker had to be equipped with the correct personal protective equipment (PPE) and given training in its use before they could start caring for patients. After donning a medical protective mask, every worker was required to ask another to check if it was sufficiently tight, and, after they took their PPE off, they used quick-drying hand sanitizer. Different levels of PPE were assigned to healthcare workers according to the severity of the patients under their care, as showed in Figure 5. Workers administering oxygen therapy to confirmed COVID-19 patients in the third sector wore level-II protection consisting of protective clothing, gloves, shoe covers, head covers, a N95 mask, and protective (anti-fog) glasses, and they also carried out hand hygiene measures. Personnel carrying out operations among patients that might be associated with aerosol generating procedures, like sampling or sputum suction, wore level III-1 protection consisting of all the above items plus a waterproof isolation gown, and a face shield and also carried out the hand hygiene procedures. Personnel caring for sectortwo patients, suffering from severe respiratory distress but not requiring invasive ventilation treatment, were also obliged to use level III-1 PPE (8). According to recent recommendations (10, 11), the highest level of PPE, level III-2, which included an air-purifying respirators (PAPRs), was reserved for high risk operations including tracheal intubation, tracheotomy, or fiberoptic bronchoscopy.

\section{Education and Training of Health Workers}

It is estimated that a considerable proportion of healthcare workers have been infected since the COVID-19 outbreak (for example, infected rates of health workers were 28603/236076 (12.1\%) in Italy (https://www.epicentro.iss.it/en/coronavirus/ bollettino/Infografica_10giugno\%20ENG.pdf). Minimizing the risk of nosocomial outbreak amplification and protecting healthcare workers are of critical importance $(8,12)$. Widespread use of recommended barrier precautions in isolated wards must be of highly priority. The temporary ICUs set up to manage the epidemic in China established protocols for both the prevention of infection and contingency management, including PPE regulations, procedures for entering and leaving quarantined zones, emergency plans to cope with occupational exposure, checks on the hygiene standards observed by healthcare workers, and management of preventive medication. It is imperative that ensuring every healthcare worker is properly trained, continually protected against droplet infection, and versed in all the necessary checks and precautions, including the use of PPE. This is vital in the battle against a highly infectious disease such as COVID-19.

\section{MANAGEMENT}

Data from a follow-up study of 99 COVID-19 cases, dated January 25, 2020, reveal that $11 \%$ died, 9\% required invasive 


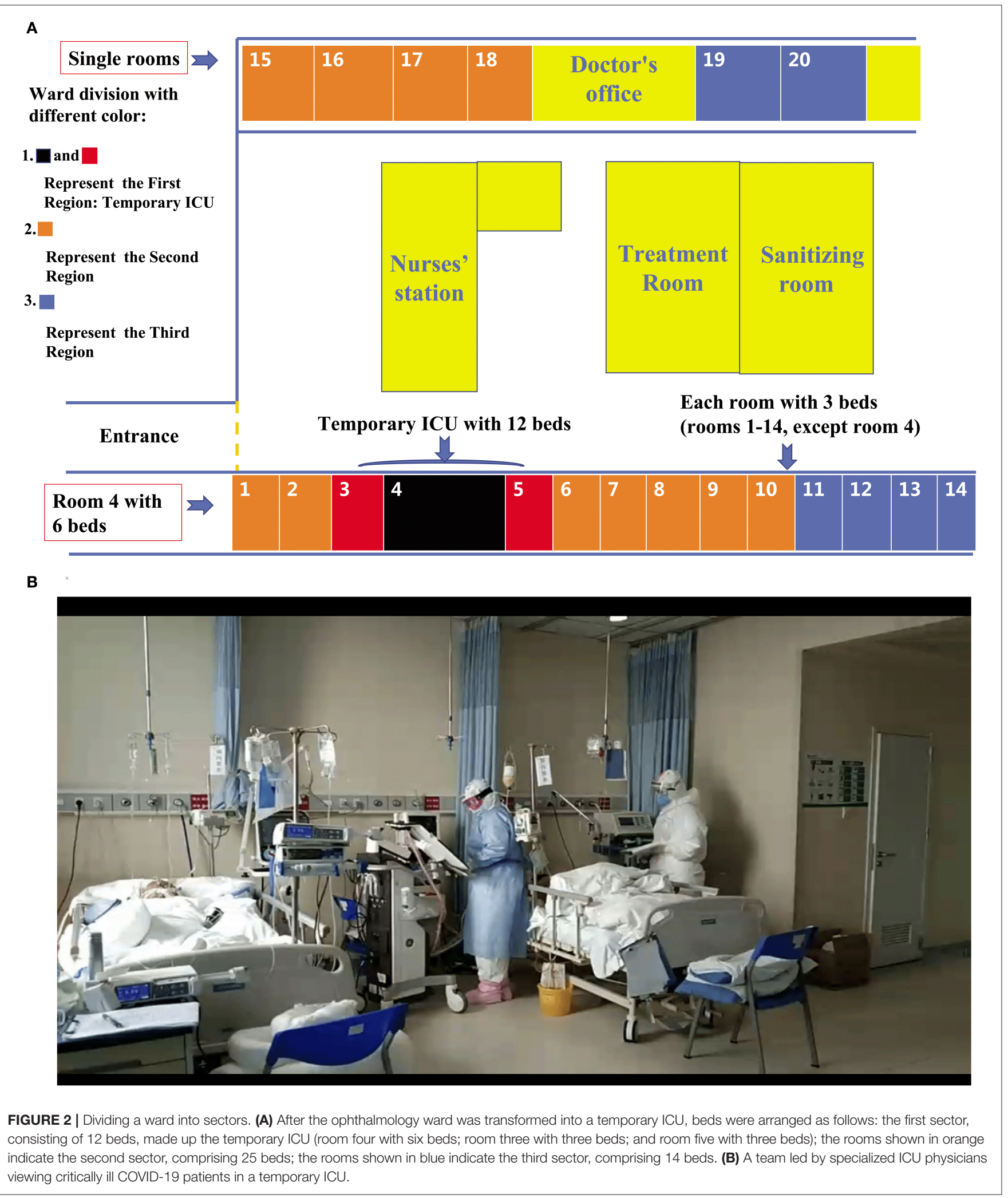

mechanical ventilation, and $3 \%$ required extracorporeal membrane oxygenation (ECMO) (13). Among the significant findings was that before January 30, 2020, only about $25 \%$ of patients who died from COVID-19 received invasive mechanical ventilation or ECMO, and that HFNC and/or non-invasive ventilation (NIV) were used for an average 


\begin{tabular}{|c|c|c|c|c|c|c|c|}
\hline \multirow[b]{2}{*}{$\begin{array}{l}\text { Situation of } \\
\text { ward }\end{array}$} & \multirow[b]{2}{*}{$\begin{array}{l}\text { Risk } \\
\text { Grading }\end{array}$} & \multicolumn{5}{|c|}{ Early classifying critical cases with COVID infection } & \multirow[b]{2}{*}{ Level of Critical Care } \\
\hline & & Score & Symbols & Nurses & $\begin{array}{l}\text { Bed/Nurs } \\
\text { e ratio }\end{array}$ & Scaled of PPE & \\
\hline $\begin{array}{l}\text { The Third } \\
\text { region }\end{array}$ & Low & $1-4$ & Blue & $\begin{array}{l}\text { One ICU nurse leads } \\
\text { a team of } 6 \text { trained } \\
\text { non-ICU nurses }\end{array}$ & $4: 1$ & Level II & Usual oxygen therapy \\
\hline $\begin{array}{l}\text { The Second } \\
\text { region }\end{array}$ & Moderate & $5-6$ & Orange & $\begin{array}{l}\text { One ICU nurse leads } \\
\text { a team of } 3 \text { trained } \\
\text { non-ICU nurses }\end{array}$ & $3: 1$ & Level III-1 & $\begin{array}{l}\text { Oxygen therapy with mask; } \\
\text { Low parameter of high- } \\
\text { flow nasal cannula }\end{array}$ \\
\hline $\begin{array}{l}\text { The First } \\
\text { region of } \\
\text { Temporary } \\
\text { ICU }\end{array}$ & Critical & $\geq 7$ & Red & $\begin{array}{l}\text { One ICU nurse leads } \\
\text { a team of } 2 \text { trained } \\
\text { non-ICU nurses }\end{array}$ & $2: 1$ & Level III-1 & $\begin{array}{l}\text { High flow or non-invasive } \\
\text { ventilation }\end{array}$ \\
\hline $\begin{array}{l}\text { The First } \\
\text { region of } \\
\text { Temporary } \\
\text { ICU }\end{array}$ & $\begin{array}{l}\text { Severe } \\
\text { critical }\end{array}$ & $\geq 7$ & Black & $\begin{array}{l}\text { One ICU nurse leads } \\
1 \text { trained non-ICU } \\
\text { nurse }\end{array}$ & $1: 1$ & $\begin{array}{l}\text { Level III-1/ } \\
\text { Level III-2 } \\
\text { (special } \\
\text { protection) }\end{array}$ & $\begin{array}{l}\text { - Consideration for early } \\
\text { invasive ventilation } \\
\text { - Lung-protective ventilation } \\
\text { strategies } \\
\text { - Prone positioning } \\
\text { - Hemodynamic monitoring }\end{array}$ \\
\hline
\end{tabular}

FIGURE 3 | Early sorting of critically ill COVID-19 patients according to a modified Early Warning Score in a temporary ICU.

\begin{tabular}{|c|c|c|c|c|}
\hline \multicolumn{5}{|c|}{ Equipment for Usual critical care in temporary ICU } \\
\hline Ward division & & $\begin{array}{l}\text { The first region (Temporary } \\
\text { ICU) }\end{array}$ & $\begin{array}{l}\text { The second } \\
\text { region }\end{array}$ & $\begin{array}{l}\text { The third } \\
\text { region }\end{array}$ \\
\hline Equipment & Details & Score $\geq 7$ & Score: $5-6$ & Score: $1-4$ \\
\hline \multirow[t]{5}{*}{ Ventilators } & invasive ventilators & + & - & - \\
\hline & no-invasive ventilators & + & + & - \\
\hline & high flow nasal cannula & + & + & - \\
\hline & renal replacement machines & + & + & - \\
\hline & extracorporeal membrane oxygenation & + & - & - \\
\hline \multirow[t]{2}{*}{ Monitors } & with CVP model & + & - & - \\
\hline & with invasive arterial blood pressure model & + & - & - \\
\hline \multirow[t]{2}{*}{ Visual equipment } & videolaryngoscopes & + & - & - \\
\hline & videobronchoscopes & + & - & - \\
\hline \multicolumn{2}{|c|}{ Ultrasound machines } & + & + & - \\
\hline \multirow{4}{*}{$\begin{array}{l}\text { Equipment for } \\
\text { nursing care }\end{array}$} & infusion pumps & + & + & + \\
\hline & syringe pumps & + & + & + \\
\hline & vibrating expectoration machines & + & + & + \\
\hline & closed tracheal suction catheters & + & + & + \\
\hline
\end{tabular}

of 6 (4-8) days before intubation or death (14). It can be inferred that invasive mechanical ventilation was delayed, possibly due to a lack of the necessary equipment, specialist staff, or areas in which the procedure could be carried out or to a fear of infection during the operation of trachea intubation.

COVID-19 is an infectious disease characterized as an acute hypoxemic respiratory insufficiency or failure which requires 


\begin{tabular}{|c|c|c|c|}
\hline \multicolumn{4}{|c|}{$\begin{array}{c}\text { Different scales of Standard personal protective equipment (PPE) for Usual critical care of confirmed COVID-19 patients in } \\
\text { temporary ICU }\end{array}$} \\
\hline \multirow[b]{2}{*}{ Equipment } & \multicolumn{3}{|c|}{ Scaled protection } \\
\hline & $\begin{array}{l}\text { Level II } \\
\text { (General Oxen therapy) }\end{array}$ & $\begin{array}{l}\text { Level III-1 } \\
\text { (Suction, pharyngeal swab sampling, NIV } \\
\text { or HFNC) }\end{array}$ & $\begin{array}{l}\text { Level III-2 } \\
\text { (Intubation, tracheotomy, } \\
\text { or bronchoscopy ) }\end{array}$ \\
\hline Waterproof isolation gowns & \pm & + & + \\
\hline Protective clothing & + & + & + \\
\hline Gloves & $+($ one or double) & $+($ double $)$ & $+($ three $)$ \\
\hline Shoe covers & + & + & + \\
\hline Head covers & + & + & + \\
\hline Face screen & - & + & + \\
\hline Medical protective masks & \pm & + & + \\
\hline N95 & + & + & + \\
\hline Protective glasses (anti-fog) & + & + & + \\
\hline $\begin{array}{l}\text { Air-purifying respirator } \\
\text { (PAPR) }\end{array}$ & - & - & + \\
\hline Hand hygiene & + & + & + \\
\hline
\end{tabular}

A

+ , mandatory; -, not needed; + , decision made according to the work scenario
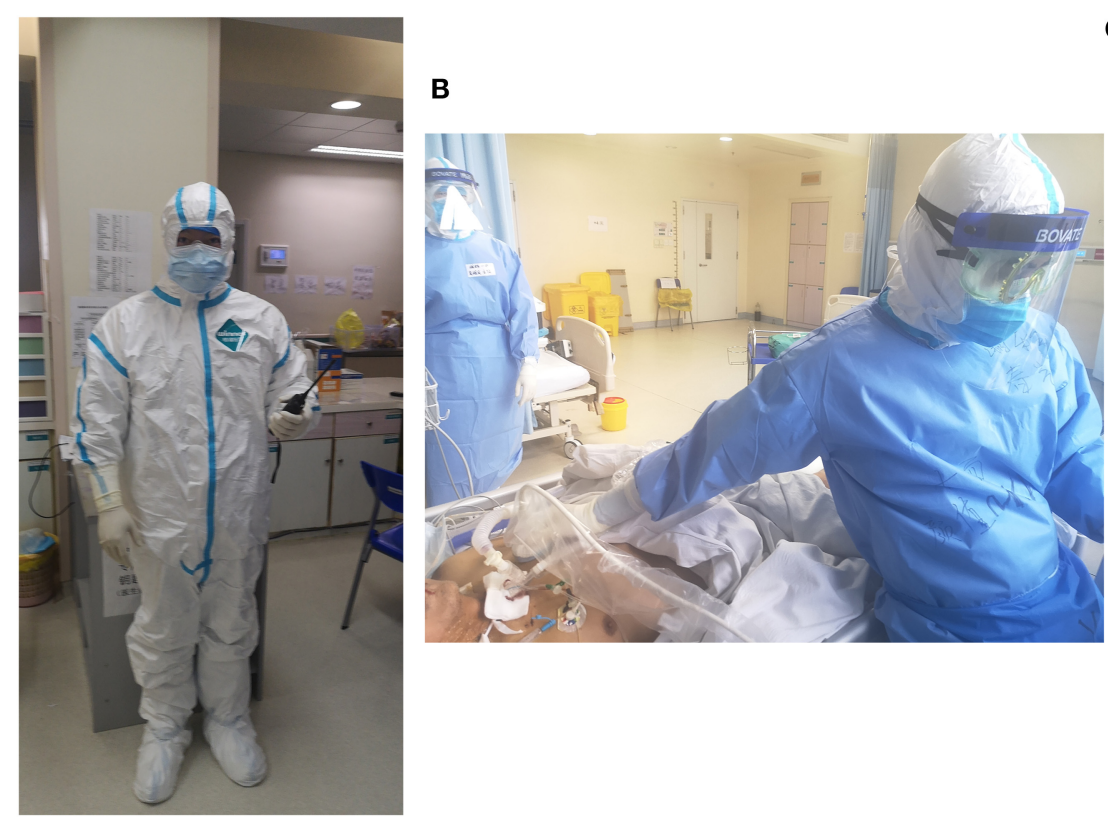

C

FIGURE 5 | Standard personal protective equipment (PPE) required for normal critical care with COVID-confirmed patients in a temporary ICU. The required standard of PPE is based on the guidelines for the prevention and control of COVID-19 infection in medical institutions laid out by the government in China. Doctors have different scales of PPE to care for severe confirmed patients in different situations. (A) A doctor with level-II PPE at the nurses' station; (B) A doctor with level III-1 PPE for ultrasonography in a temporary ICU; (C) Two doctors with level III-2 PPE preparing for percutaneous tracheostomy in a temporary ICU.

the use of oxygen and ventilation therapies. Most infected patients suffer mild symptoms and are self-healing; however, in severe cases, progression is rapid and can lead to ARDS, septic shock, metabolic acidosis, and coagulopathy (15), especially when combined with old age, comorbidities, or persistent lymphocytopenia, which is difficult to correct. As standardizing the management of care is a vital element in improving survival rates, the National Health Commission of the People's Republic of China (http://www.nhc.gov.cn/yzygj/s7653p/ 202002/d4b895337e19445f8d728fcaf1e3e13a.shtml) and the WHO (https://www.who.int/docs/default-source/coronaviruse/ clinical-management-of-novel-cov.pdf) have established a 


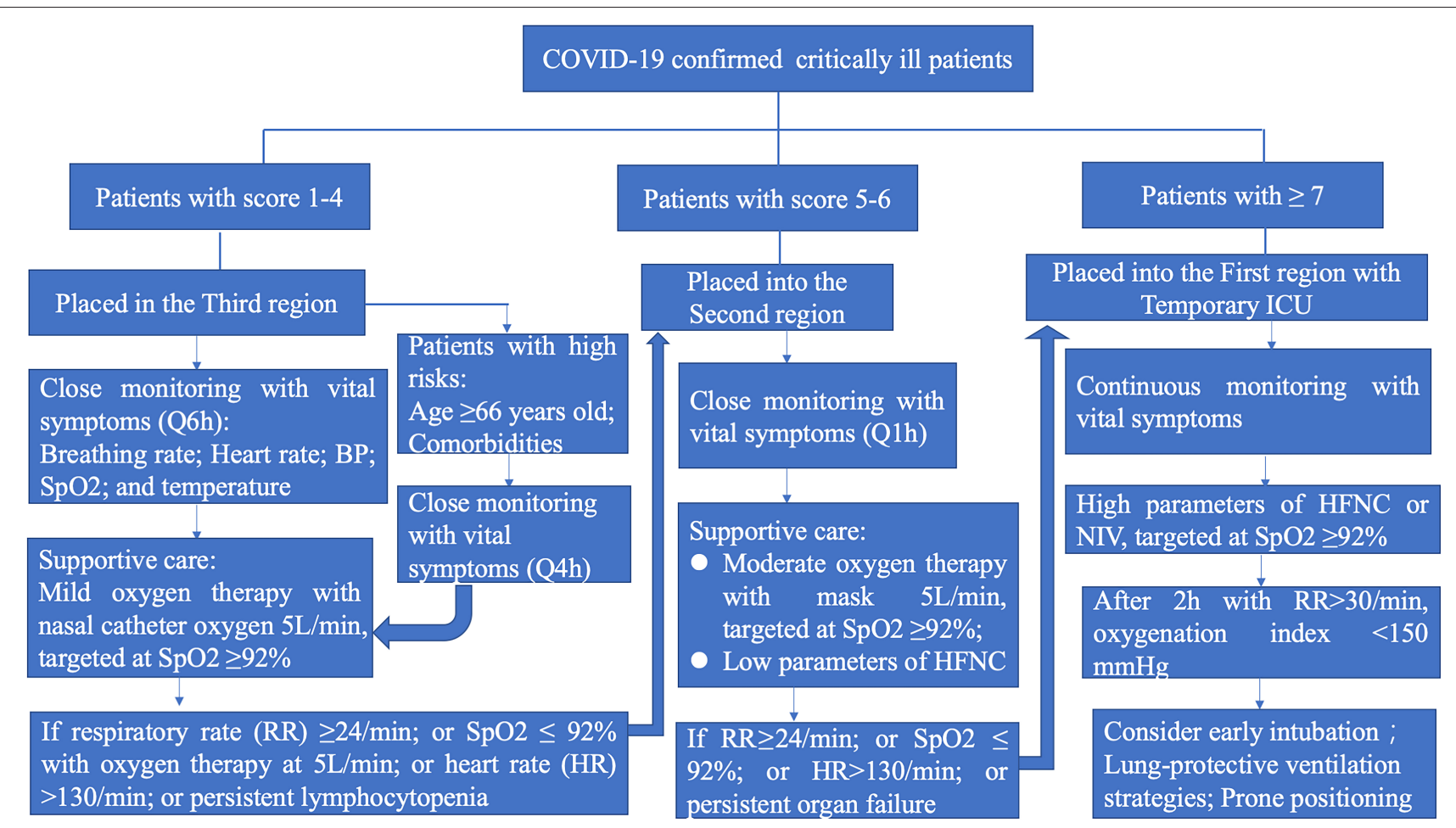

FIGURE 6 | The management algorithm based on the clinical severity of critically ill COVID-19 patients. HFNC, high flow nasal cannula; NIV, non-invasive ventilation.

protocol for the treatment of COVID-19. Timely and effective airway management and maximized first-pass success rate of airway operation for COVID-19 patients are recommended $(8,11)$.

For patients in the third sector of the temporary ICU (who have mild symptoms), healthcare workers must give supportive care and ensure monitoring at 6-h intervals of the vital symptoms, such as breathing rate, oxygen saturation (SpO2), and heart rate. Oxygen therapy should be initiated at $5 \mathrm{~L} / \mathrm{min}$ and titrated to $\mathrm{SpO} 2 \geq 92 \%$ in COVID-19 patients. For patients with high risk factors ( $\geq 66$ years old and comorbidities), nurses must ensure close monitoring of vital symptoms at 4 -h intervals. In the following conditions, patients must be swiftly transferred to the second (moderate) sector, in case they need HFNC oxygenation or NIV: breathing rate $\geq 24 / \mathrm{min}, \mathrm{SpO} 2<92 \%$ with oxygen therapy at $5 \mathrm{~L} / \mathrm{min}$, or heart rate $>130 / \mathrm{min}$, or persistent lymphocytopenia. Throughout treatment, conservative intravenous fluid strategies must be strictly implemented unless septic shock occurs.

In the case of severe patients with persistent respiratory distress, a respiratory rate $>30 / \mathrm{min}$, oxygenation index $<150$ $\mathrm{mmHg}$, or showing no improvement after HFNC or NIV, continuous monitoring is necessary from an experienced ICU team. The vital symptoms must be monitored after HFNC or NIV treatment at intervals of no more than $2 \mathrm{~h}(16)$. If there is no improvement after $2 \mathrm{~h}$, or the patient's condition worsens, the team should consider early invasive ventilation (8), followed by lung-protective ventilation strategies and early prone positioning during mechanical ventilation for more than 12 hours per day (Figure 6).

\section{CONCLUSIONS}

The sudden outbreak of the highly contagious disease now known as COVID-19 in China in December 2019 has impacted healthcare system and societies more widely across the world. Should another virus of this type emerge, it will be vital to first control the source of infection and second prevent transmission. Moreover, the identification, sorting, and management of infected patients in different isolated sectors according to level of severity is crucial in ensuring full use is made of the medical resources available. Public anxiety around COVID-19 centers on the large numbers of critically ill patients and high death rates. In this regard, setting up a temporary ICU in isolated hospitals, run by multidisciplinary staff under the leadership of intensive care specialists and nurses, is crucial not only in caring for critically ill patients and bringing down mortality rates, but also in allaying public fear.

\section{DATA AVAILABILITY STATEMENT}

The original contributions presented in the study are included in the article/supplementary material, further inquiries can be directed to the corresponding author/s. 


\section{AUTHOR CONTRIBUTIONS}

MP contributed to the literature search, figures, writing of the original draft, and project administration of the manuscript. ZQ and LZ contributed equally to the conceptualization, data and resource curation, supervision, validation, and writing, reviewing, and editing of the research.

\section{REFERENCES}

1. Wu Z, McGoogan JM. Characteristics of and important lessons from the coronavirus disease 2019 (COVID-19) outbreak in China: summary of a report of 72314 cases from the Chinese Center for Disease Control and Prevention. JAMA. (2020) 323:1239-42. doi: 10.1001/jama.2020.2648

2. Yang X, Yu Y, Xu J, Shu H, Xia J, Liu H, et al. Clinical course and outcomes of critically ill patients with SARS-CoV-2 pneumonia in Wuhan, China: a single-centered, retrospective, observational study. Lancet Respir Med. (2020) 8:475-81. doi: 10.1016/S2213-2600(20)30079-5

3. Murthy S, Gomersall CD, Fowler RA. Care for critically ill patients with COVID-19. JAMA. (2020) 323:1499-500. doi: 10.1001/jama.2020.3633

4. Maves RC, Jamros CM, Smith AG. Intensive care unit preparedness during pandemics and other biological threats. Crit Care Clin. (2019) 35:60918. doi: 10.1016/j.ccc.2019.06.001

5. Liao $X$, Wang B, Kang Y. Novel coronavirus infection during the 2019-2020 epidemic: preparing intensive care units-the experience in Sichuan Province, China. Intensive Care Med. (2020) 46:357-60. doi: 10.1007/s00134-020-05954-2

6. Smith ME, Chiovaro JC, O’Neil M, Kansagara D, Quinones AR, Freeman M, et al. Early warning system scores for clinical deterioration in hospitalized patients: a systematic review. Ann Am Thorac Soc. (2014) 11:145465. doi: 10.1513/AnnalsATS.201403-102OC

7. Wang D, Hu B, Hu C, Zhu F, Liu X, Zhang J, et al. Clinical characteristics of 138 hospitalized patients with 2019 Novel Coronavirus-Infected Pneumonia in Wuhan, China. JAMA. (2020) 323:1061-69. doi: 10.1001/jama.2020.1585

8. Sorbello M, El-Boghdadly K, Di Giacinto I, Cataldo R, Esposito C, Falcetta S, et al. The Italian coronavirus disease 2019 outbreak: recommendations from clinical practice. Anaesthesia. (2020) 75:724-32. doi: 10.1111/anae.15049

9. Ruan Q, Yang K, Wang W, Jiang L, Song J. Clinical predictors of mortality due to COVID-19 based on an analysis of data of 150 patients from Wuhan, China. Intensive Care Med. (2020) 46:846-8. doi: 10.1007/s00134-020-05991-x

10. Orser BA. Recommendations for Endotracheal Intubation of COVID-19 Patients. Anesth Analg. (2020) 130: 110910. doi: 10.1213/ANE.0000000000004803
All authors contributed to the article and approved the submitted version.

\section{ACKNOWLEDGMENTS}

We would like to thank all the health workers for their efforts in our Temporary ICU.

11. Cook TM, El-Boghdadly K, McGuire B, McNarry AF, Patel A, Higgs A Consensus guidelines for managing the airway in patients with COVID19: guidelines from the Difficult Airway Society, the Association of Anaesthetists the Intensive Care Society, the Faculty of Intensive Care Medicine and the Royal College of Anaesthetists. Anaesthesia. (2020) 75:78599. doi: 10.1111/anae.15054

12. Adams JG, Walls RM. Supporting the health care workforce during the COVID-19 global epidemic. JAMA. (2020). doi: 10.1001/jama.2020.3972

13. Chen N, Zhou M, Dong X, Qu J, Gong F, Han Y, et al. Epidemiological and clinical characteristics of 99 cases of 2019 novel coronavirus pneumonia in Wuhan, China: a descriptive study. Lancet. (2020) 395:507-13. doi: 10.1016/S0140-6736(20)30211-7

14. Xie J, Tong Z, Guan X, Du B, Qiu H, Slutsky AS. Critical care crisis and some recommendations during the COVID-19 epidemic in China. Intensive Care Med. (2020) 46:837-40. doi: 10.1007/s00134-02005979-7

15. Robba C, Battaglini D, Ball L, Patroniti N, Loconte M, Brunetti I, et al. Distinct phenotypes require distinct respiratory management strategies in severe COVID-19. Respir Physiol Neurobiol. (2020) 279:103455. doi: 10.1016/j.resp.2020.103455

16. Zuo MZ, Huang YG, Ma WH, Xue ZG, Zhang JQ, Gong YH, et al. Expert recommendations for tracheal intubation in critically ill patients with Noval Coronavirus Disease 2019. Chin Med Sci J. (2020) 35:1059. doi: $10.24920 / 003724$

Conflict of Interest: The authors declare that the research was conducted in the absence of any commercial or financial relationships that could be construed as a potential conflict of interest.

Copyright (c) 2020 Peng, Qian and Zhang. This is an open-access article distributed under the terms of the Creative Commons Attribution License (CC BY). The use, distribution or reproduction in other forums is permitted, provided the original author(s) and the copyright owner(s) are credited and that the original publication in this journal is cited, in accordance with accepted academic practice. No use, distribution or reproduction is permitted which does not comply with these terms. 